Revista lus et Praxis, Año 17, No 2, 2011, pp. 283 - 304

ISSN 0717 - 2877

Universidad de Talca - Facultad de Ciencias Jurídicas y Sociales

"Principios de competencia judicial internacional y de protección del medio ambiente"

Pía Moscoso Restovic

\title{
PRINCIPIOS DE COMPETENCIA JUDICIAL INTERNACIONAL Y DE PROTECCIÓN DEL MEDIO AMBIENTE*
}

\author{
PRINCIPLES OF INTERNATIONAL JURISDICTION AND ENVIRONMENTAL PROTECTION
}

\author{
Pía Moscoso Restovic ${ }^{* *}$
}

\begin{abstract}
RESUMEN
¿Cómo se resuelve el problema de la objetivación del vínculo de conexión cuando intervienen daños civiles y daños ambientales? Es decir, ¿podemos sostener que el fuero "lugar del hecho dañoso" puede determinarse con independencia de los sujetos que intervienen? ¿Es relevante el principio favor laesi en los casos de daño ambiental? Proponemos abordar estos problemas desde la relación que existe entre los principios de Competencia Judicial Civil Internacional y los principios de protección del medio ambiente.
\end{abstract}

Así, advertiremos que la mayor o menor extensión del fuero "lugar del hecho dañoso", adquiere connotaciones especiales si interpretamos armónicamente los principios de competencia judicial internacional y los principios de protección internacional del medio ambiente.

En efecto, la política de protección ambiental, constituye un "valor superior del ordenamiento", y por tanto incide directamente en el juicio razonabilidad que el juez debe realizar sobre el vínculo de conexión.

Si bien abordamos el problema desde la experiencia europea, las conclusiones tendrán validez universal.

\section{ABSTRACT}

How to solve the problem of objectivity in the link between the court and the action, when engaging civil damages and environmental damages? In other words $i$ can we argue that the place of the harmful event can be determined independently of the persons involved? ¿ls favor laesi principle relevant in cases of environmental damage?

We propose analyze those problems through the connections between International Civil Jurisdiction principles and environmental protection principles. In fact, environmental protection policy constitutes a "superior value". Therefore it affects directly the judge opinion about the connection link.

\footnotetext{
* El presente artículo ha sido desarrollado durante el período de Investigación en uso de Comisión de Estudios otorgada por la Universidad de Atacama para el Doctorado en Derecho Internacional y Relaciones Internacionales de la Universidad Complutense de Madrid. Fecha de conclusión del artículo, mayo de 2011. Trabajo recibido el 13 de mayo y aprobado el 20 de julio de 2011.

** Abogada; Magíster en Derecho de Minas, Aguas y Medio Ambiente, Universidad de Atacama Chile; Doctor (c) Derecho Internacional y Relaciones Internacionales, Universidad Complutense de Madrid España; Profesora de Derecho Privado de la Universidad de Atacama. Correo electrónico: pia. moscoso@uda.cl.
} 
Our approach is European, but the findings have universal validity.

PALABRAS CLAVE

Derecho Internacional Privado, Competencia Judicial Internacional, Daño Ambiental Internacional, Responsabilidad por Actos llícitos, Hecho Dañoso

KEYWORDS

Private International Law, International Jurisdiction, International Environmental Damage, Liability for Wrongful Acts, Harmful Event

\section{INTRODUCCIÓN}

La Competencia Judicial Civil Internacional $(\mathrm{CJCl})$, regulada en el Derecho europeo, a través del Reglamento 44/2001 Bruselas I (sobre competencia judicial, el reconocimiento y la ejecución de resoluciones judiciales en materia civil y mercantil), constituye el marco fundamental para el desarrollo del debate sobre los fueros especiales en materia de competencia internacional por daño ambiental. En efecto, el artículo 5.3 del Reglamento 44/2001 Bruselas I, es el que -hasta ahora- regula la materia, por pronunciarse sobre los delitos y cuasidelitos civiles.

Sin embargo, el desarrollo jurisprudencial del Tribunal de Justicia de las Comunidades Europeas (TJCE), ha debido recurrir a la fundamentación axiológica y teleológica de los principios de Derecho comunitario (principalmente de Derecho internacional privado) para determinar el contenido y la extensión de los fueros especiales de competencia judicial internacional, llegando incluso a establecer interpretaciones autónomas sobre la materia.

Por esta razón se estima de suma relevancia promover un debate a partir de los principios que se encuentran ínsitos en las normas de CJCl. En efecto, en materia ambiental, la disciplina se encuentra en constante evolución, por esta razón, un debate con perspectivas de futuro -y validez universal--, debe basarse, tanto en los principios, como en las normas instrumentales que coadyuvan en la argumentación jurídica. Como lo señala el título de este trabajo, nos dedicaremos a los principios que el juez deberá tener en consideración al momento de pronunciarse tanto en la reclamación, como en la declinación de su competencia judicial internacional.

\section{PRINCIPIOS DE COMPETENCIA JUDICIAL INTERNACIONAL}

\section{Principio de proximidad razonable}

La CJCl referida a los ilícitos ambientales constituye un foro de naturaleza patrimonial especial, que es tributario de las características generales que se atribuyen a esta clase de foros de naturaleza patrimonial en el modelo de justi- 
cia privada europea, a saber: a) obedece al principio de proximidad razonable, b) sigue una tipificación legal y c) tiene una relación de subsidiariedad formal con el foro general (domicilio del demandado) ${ }^{1}$. Por su relevancia abordaremos el primero de ellos.

El principio de proximidad razonable no ha sido expresamente establecido para el fuero del artículo 5.3 del Reglamento 44/2001 Bruselas I. No obstante, el Reglamento Bruselas I, regulando la CJCl por conexidad, esto es, regulando aquella competencia establecida para casos que presentan entre sí vínculos estrechos de naturaleza procesal, ha establecido criterios de proximidad razonable basados en la "economía procesal". En efecto, se ha justificado el conocimiento acumulado de los asuntos con el objeto de evitar sentencias contradictorias. Desde esta perspectiva, la proximidad razonable es un principio del Derecho internacional privado. Este principio ha sido profusamente desarrollado tanto a nivel doctrinal ${ }^{2}$, como a nivel jurisprudencial ${ }^{3}$.

Desde la perspectiva del daño civil internacional extracontractual asociado a un daño ambiental, resulta necesario recurrir a criterios que asisten en la determinación de los vínculos más estrechos que presenta el asunto con un

\footnotetext{
1 VIRGÓs Soriano, Miguel; Garcimartín Alférez, Derecho Procesal Civil Internacional Litigación Inter-

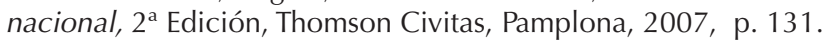

2 LaGARDE, Paul, "Le principe de proximité dans le droit international privé contemporain", Recueil des cours de l'Académie de Droit International de La Haye T. 196, 1986, p.150 y ss. Fallon, Marc, "Le principe de proximité dans le droit de l'Union européenne", en LaGarde, Mélanges P., Dalloz, París, 2005, p. 241-262. Fallon, Marc, "Les conditions d'un code européen de droit international privé", en La matière civile et commerciale, socle d'un code européen de droit international privé?, M. FALLON, P. LAGARDE et S. Poillot-Peruzzetto ed(s), Paris, Dalloz, 2009, p. 1-34. Otero García-Castrillón, Carmen, "Problemas de aplicación de las normas de competencia judicial internacional en el Derecho español y comunitario: reflexiones en torno a la doctrina del forum non conveniens", Revista de la Facultad de Derecho de la Universidad Complutense, № 94, 2000, pp. 99-128. Calvo CaravaCA, Alfonso-Luis, "El Derecho internacional privado en la comunidad europea", Anales del Derecho, Universidad de Murcia, № 21, 2003, pp. 49-69; Virgós Soriano, Miguel y Garcimartín Alférez, Francisco, ob. cit., p. 55; Pérez Vera, Elisa y González Campos, Julio, Derecho Internacional Privado, Vol. I, UNED, España, UNED, 2001, pp. 291- 317, GaRAu Sobrino, Federico, Lecciones de Derecho Procesal Civil Internacional, España Universitat de les Illes Balears, 2003, p. 26. RodríGuez Jiménez, Sonia, Competencia Judicial Internacional, Instituto de Investigaciones Jurídicas, Universidad Nacional Autónoma de México 2009, pp. 61-68; RodríGuez JiméNEZ, Sonia, Conexidad y Litispendencia Internacional en el Derecho internacional privado mexicano, Instituto de Investigaciones Jurídicas, Universidad Nacional Autónoma de México, 2009, pp. 120-213.

3 STJCE 56/79, asunto Zelger vs. Salinitri. STJCE C-256/00, asunto Besix SA, apartados 31-35. STJCE C-167/00 caso Henkel. STJCE C4/03, asunto Gesellschaft für Antriebstechnik mbH \& Co. KG y Lamellen und Kupplungsbau Beteiligungs KG, apartado 21. STJCE C343/04, asunto Land Oberösterreich contra EZ, apartados 27-29. STJCE C73/04, asunto Brigitte y Marcus Klein y Rhodos Management Ltd., apartados 14-16. Conclusiones del Abogado General Sr. F.G. Jacobs, de 18 de septiembre de 2003, C-18/02, Asunto DFDS Torline A/S contra SEKO Sjöfolk Facket för Service og Kommunikation. Conclusiones del Abogado General Sr. Paolo Mengozzi, de 24 de mayo de 2007, C98/06, asunto Freeport plc contra Olle Arnoldson. Conclusiones del Abogado General Sr. L.A. Geelhoed de 31 de enero de 2002, C-334/00, asunto Fonderie Officine Meccaniche Tacconi Spa, apartados 28-30.
} 
Estado determinado. En estos casos es necesario preguntarse por la naturaleza y las características de tales vínculos. En efecto, el Principio de proximidad razonable invita al análisis holístico de todos los vínculos. Por esta razón, debe tenerse especial cuidado, porque no cualquier vínculo es suficiente para determinar la competencia judicial de un tribunal. Consideramos oportuno realizar un esfuerzo sistemático. En efecto, existe multiplicidad de vínculos que deben considerarse al momento de determinar el foro competente:

i) Existen vínculos que se relacionan con los elementos de la obligación extracontractual, aquí encontramos a: los sujetos involucrados, el daño ocasionado, la acción causante del daño y la negligencia (según el modelo de responsabilidad ambiental que se trate). Para el legislador del Reglamento 44/2001 Bruselas I, sólo uno de los elementos de la relación extracontractual define el tribunal competente: el hecho dañoso. Considerando que el foro establecido en el artículo 5.3 del Reglamento 44/2001 Bruselas I es especial, ha desplazado a los demás elementos de la relación extracontractual. Para los casos de ilícitos ambientales y civiles directamente asociados, el posicionamiento del punto de conexión en el daño, es de suyo decidor sobre la importancia del resultado, definiendo la carga de la internacionalidad.

ii) Existen vínculos que guardan relación con los elementos de la relación procesal internacional, aquí encontramos: el domicilio de las partes, la ley procesal aplicable, la ley de fondo aplicable, el lugar de ejecución de la sentencia, el lugar de producción de pruebas, el lugar donde se practicarán medidas cautelares, en suma lugares que aconseja la economía procedimental ${ }^{4}$. Tales vínculos viven subyacentes en las normas del Reglamento 44/2001 Bruselas I e informan una interpretación restrictiva de los fueros especiales propendiendo a la minimización tanto del forum shopping como del law shopping.

La primacía que se entregue a estos criterios perjudicará al demandante civil directo por hechos ambientalmente contaminantes, en la medida que no se asocien los principios de protección ambiental internacional.

iii) Existen vínculos que nacen de los criterios generales de imputación de riesgos dentro de la lógica del Derecho internacional privado, aquí encontramos: la prioridad reconocida a la autonomía de la voluntad, la valoración de la buena fe de los litigantes internacionales, el beneficio de las cargas de la prueba para una de las partes, existencia de presunciones y la protección de la apariencia de buen derecho. El Reglamento 44/2001 Bruselas I no es claro en la imputación de los riesgos a una sola de las partes de la relación civil extracontractual internacional. Por otra parte, ha sido consistente en señalar que no existe un

${ }^{4}$ Sentencias que aluden a la economía procesal para fundar sus fallos en: STJCE C-116/02, asunto Erich Gasser GmbH vs. MISAT Srl., apartado 38. STJCE C539/03, asunto Roche Nederland BV y otros vs. Frederick Primus, Milton Goldenberg, apartado 36. 
principio favor laesi en beneficio de la víctima de daño extracontractual. Sin embargo, en caso de daños ambientales, es evidente que el juicio de reproche a la conducta del demandado altera sustancialmente la carga de la internacionalidad, haciéndola recaer en el demandado.

En efecto, la "regla de la ubicuidad" del hecho dañoso, establecida por la sentencia Bier vs. Minas de Potasio de Alsacia, hizo que la imputación de los riesgos recaiga en el demandado. Corresponde analizar en cada caso concreto si la extensión de dicha regla es clara y si las limitaciones establecidas para los daños civiles por parte de la jurisprudencia del TJCE pueden aplicarse a los daños civiles asociados a un daño ambiental y la conveniencia de todo ello para el sistema comunitario de distribución de competencias ${ }^{5}$.

iv) Finalmente, existen vínculos que son una respuesta a la demanda de flexibilidad del sistema, y que se justifican en el derecho de tutela judicial efectiva. Tal es el caso del llamado foro de necesidad. Sin embargo, en materia de daños ambientales y en materia de daños civiles asociados, encontramos que este foro no tiene ni consagración legal ni reconocimiento jurisprudencial. De aquí que sean las jurisprudencias nacionales las que lleven el peso de dotar de contenido al derecho de tutela judicial efectiva para casos de daño ambiental y de daño civil asociado. Gran parte de ese peso es soportado por la jurisdicción civil extracontractual nacional. Por esta razón pervive la importancia de dotar a la jurisdicción que conoce de casos de responsabilidad civil por daño extracontractual de criterios que sean adecuados a las disciplinas ambientales y al avance internacional en la materia.

Como se advierte, en este esfuerzo por sistematizar vínculos de jurisdicción en atención a sus criterios, tenemos que la cantidad y variedad de vínculos existentes entre el caso y un tribunal es heterogénea y puede llegar a ser bastante compleja. De aquí surge la necesidad de configurar un Principio de proximidad razonable en materia de $\mathrm{CJCl}$, respetuoso de los principios ambientales internacionales.

En el sistema competencial europeo ${ }^{6}$ puede dilucidarse un mayor consenso sobre el título de jurisdicción, pero subsiste la incertidumbre frente a casos de

\footnotetext{
5 El debate sobre la importancia de determinar el punto de conexión también se extiende a la ley aplicable, conforme al Reglamento Roma II, conforme al cual la lex loci delicti también se reconoce como una regla de alternatividad.

${ }^{6}$ Cuerpos normativos: a) Convenio de Bruselas, de 27 de septiembre de 1968, relativo a la competencia judicial y a la ejecución de resoluciones judiciales en materia civil y mercantil. Modificado respectivamente por los Convenios de Adhesión; b) Convenio de Lugano, de 16 de septiembre de 1988, relativo a la competencia judicial y a la ejecución de resoluciones judiciales en materia civil y mercantil. Amplía el ámbito de aplicación del Convenio de Bruselas de 1968 a determinados Estados miembros de la Asociación Europea de Libre Comercio; c) Acuerdo entre la Comunidad Europea y el Reino de Dinamarca relativo a la competencia judicial, el reconocimiento y la ejecución de resoluciones judiciales en materia civil y mercantil. Sustituido por el Convenio de Bruselas de 1968 y firmado
} 
connotación ambiental, debido a que, salvo el caso Bier vs. Minas de Potasio de Alsacia, no han llegado otros asuntos al TJCE. En efecto, aun en los casos de sistemas integrados de atribución de competencias, pueden existir sendas diferencias en los modelos de Derecho Internacional Privado vigentes en cada Estado ${ }^{7}$. Por esta razón el principio de proximidad razonable debe ser revisado para casos de daños ambientales y civiles asociados, atendida la especificidad que los criterios de protección ambiental aportan a la perspectiva de la víctima.

Un concepto relacionado con el principio de proximidad razonable es el de "previsibilidad" en el título de jurisdicción. Cuando hablamos de proximidad también realizamos un juicio sobre el grado de previsibilidad en el sistema. En efecto, el sistema de distribución de competencias jurisdiccionales debe ser previsible para las partes. En el sistema europeo, la asociación del vínculo de conexión por la definición del lugar del hecho dañoso, hace que los riesgos por la comisión del delito sean atribuidos a la parte que comete el hecho dañoso. Los resultados esperados, son: reducción de los conflictos de competencia, uniformidad del sistema comunitario, e incluso la apertura de un "mercado del riesgo" asociado al funcionamiento de un sistema internacional de seguros. Estos beneficios son innegables para los casos de daño ambiental internacional.

Por su parte, la jurisprudencia del TJCE ${ }^{8}$ y el Reglamento Bruselas $I^{9}$, se refieren a la "carga de la internacionalidad jurisdiccional", íntimamente ligada con el juicio de "previsibilidad" que tuvo el demandado, tanto en la comisión del daño, como en su localización. En materia de daños ambientales internacionales, resulta de sumo interés la asociación de la carga de la internacionalidad procesal con el juicio de reproche que recae sobre el demandado en materia de previsibilidad del daño. Mientras esta última está asociada al conocimiento científico disponible y es tratada desde la perspectiva de la negligencia como uno más de los elementos de la obligación extracontractual; en materia competencial, en cambio, el juicio de reproche alude a la mediana previsibilidad que el demandado pudo tener en la comisión del resultado dañoso y de cómo este último terminó extendiéndose a otro Estado, afectando con ello el vínculo de conexión con la jurisdicción.

en Bruselas el 19 de octubre de 2005, y finalmente, d) Reglamento (CE) № 44/2001 del Consejo, de 22 de diciembre de 2000, relativo a la competencia judicial, el reconocimiento y la ejecución de resoluciones judiciales en materia civil y mercantil (Bruselas I).

7 Los Estados pueden tener modelos muy heterogéneos basados en: la soberanía, la justicia privada o de normas abstracto generales.

8 STJCE 33/78 Asunto Somafer vs. Saar-Feerngas. STJCE C-26/91 asunto Jakob Handte vs. Mecano Chimoques. STJCE C-440/97 asunto GIE Groupe Concorde y otros vs. Capitaine commandant le navire "Suhadiwarno Pnajan" y otros. STJCE C-96/00 asunto Rudolf Gabriel. STJCE C-256/00 asunto Besix. STJCE C-334/00 asunto Fonderie Officine Meccaniche Tacconi SpA.

${ }_{9}$ Considerando $11^{\circ}$ del Reglamento Bruselas I. 
Por su parte, el daño ambiental puede verificarse a distancia del lugar de origen o manifestar sus consecuencias mucho tiempo después de haber ocurrido el hecho principal. Todo lo anterior, incide en el juicio de previsibilidad y por ello estimamos indispensable que el juez realice el juicio de razonabilidad, en forma separada al de previsibilidad, considerando a este último como un vínculo más. Por su parte, siendo la previsibilidad parte del juicio de reproche sobre la conducta del demandado, se desarrollará mejor si es abordada como elemento de la obligación extracontractual.

Finalmente, la doctrina ${ }^{10}$ acusa el riesgo de apertura de foros basados en competencias limitadas, cuando el juicio de razonabilidad se entrega a "criterios materiales" fundados en la imputabilidad del caso en concreto. Así, nace el riesgo de abrir foros especiales derivados de vínculos puntuales con un determinado Estado con competencias limitadas, y que obedecen, en general, a un fenómeno mayor: los foros especiales en razón de la materia. La proliferación de foros especiales en razón de la materia obliga al análisis en detalle de la extensión del vínculo que alega el demandante. En nuestro caso, existe un foro especial (lugar donde se produjo o pudiere producirse el hecho dañoso), cuyas competencias no están limitadas, teniendo la aptitud de desplazar al foro general (domicilio del demandado); y que, por tales motivos propende al conocimiento de todas las dimensiones del caso. De aquí la importancia de contar con la mayor certeza posible sobre el lugar donde se produjo o pudiere producirse el hecho dañoso ${ }^{11}$.

Por tanto, y atendidos los matices que se evidencian en materia de daños civiles asociados a daños ambientales internacionales, resulta que el principio de proximidad razonable, cuenta con ciertas características obligatorias.

Primero, desarrollar la proximidad asegurando la neutralidad y prudencia a fin de asegurar el derecho fundamental de tutela judicial civil, tanto para demandante como para demandado.

Segundo, cuando hablamos de razonabilidad nos estamos refiriendo a evitar los extremos que se producen en las posiciones de competencia por exceso y competencia por defecto, en cuyos casos se evidencian efectos nocivos para el buen funcionamiento del sistema comunitario ${ }^{12}$. Sin embargo, la razonabilidad en el vínculo no sólo deberá obedecer al efecto útil del sistema de distribución

\footnotetext{
10 Virgós y Garcimartín, ob. cit., p. 75.

11 Riesgos asociados a la apertura de foros especiales en razón de la materia en VIRGÓs y GARCIMARTíN, ob. cit., p. 132.

12 Perspectiva general sobre la previsión normativa y contextualizada de las reglas de competencia judicial internacional en: Rodríguez JiméNez, Sonia, "La Competencia Judicial Internacional. Dos aspectos para reflexionar", Revista de la Facultad de Derecho de México № 251, 2009, pp. 313-350.
} 
de competencias ${ }^{13}$, sino además, a cumplir los fines de justicia ambiental señalados por el constituyente y por el legislador comunitario. Al respecto, algunos autores han señalado que el juicio de razonabilidad conforme al cual se inclina la balanza por los intereses de una de las partes en la relación jurídica internacional, puede obedecer a una política asociada a los "valores superiores del ordenamiento" 14 . Tal argumento, ha llegado a justificar en algunos casos a los denominados "foros de protección".

Sin embargo, el Derecho Internacional Privado no es proclive a la apertura de un foro especial por cualquier litigio civil asociado a un daño ambiental. Tradicionalmente, no ha sido proclive a la creación de los Ilamados "foros exorbitantes"15.

\section{Principio favor laesi y coherencia con el foro general domicilio del demandado}

El fuero territorial domicilio del demandado o actor rei forum sequitur ${ }^{16}$, es un principio general recogido en el Reglamento 44/2001 Bruselas I, que obliga al demandante a presentar su demanda ante el domicilio del demandado ${ }^{17}$. Como principio, es garante de la previsibilidad en las reglas de competencia judicial internacional ${ }^{18}$ y propende a fines de seguridad jurídica en el título de jurisdicción establecidos por la propia jurisprudencia del TJCE ${ }^{19}$.

\footnotetext{
${ }^{13}$ Con miras al efecto útil del sistema comunitario la jurisprudencia del TJCE, ha rechazado la doctrina del forum non conveniens y ha prohibido las antisuit-injunctions.

14 Fernández Arroyo, Diego, "Competencia internacional exclusiva y exorbitante de los jueces de los Estados miembros de la Unión Europea ¿hasta cuándo?", Jurídica: Anuario del Departamento de Derecho de la Universidad Iberoamericana, №34, 2004, p. 61.

15 Romero Seguel, Alejandro, "La falta de jurisdicción y la denuncia en el proceso: las excepciones procesales y materiales", Revista Chilena de Derecho, Vol. 31, № 1 2004, p. 187.

16 Actor rei forum, sive in rem sive in personam sit actio, sequitur. Corpus luris 3,19, 3.

17 Principio recogido desde el Convenio de Bruselas de 27 de septiembre de 1968 y en el Convenio de Lugano de 16 de septiembre de 1988. Actualmente en el Reglamento 44/2001 del Consejo, de 22 de diciembre de 2000, y en el Convenio de 30 de octubre de 2007, todos ellos relativos a la competencia judicial, el reconocimiento y la ejecución de resoluciones judiciales en materia civil y mercantil.

${ }^{18}$ Considerando $11^{\circ}$ Bruselas I: "Las reglas de competencia judicial deben presentar un alto grado de previsibilidad y deben fundamentarse en el principio de que la competencia judicial se basa generalmente en el domicilio del demandado y esta competencia debe regir siempre, excepto en algunos casos muy concretos en los que la materia en litigio o la autonomía de las partes justifique otro criterio de vinculación. Respecto de las personas jurídicas, debe definirse el domicilio de manera autónoma para incrementar la transparencia de las reglas comunes y evitar los conflictos de jurisdicción.

19 Ver desarrollo del foro general domicilio del demandado en: STJCE, C89/91, Rec. p. I139, asunto Shearson Lehman Hutton, apartado 14. STJCE C265/02, Rec. p. I1543, asunto Frahuil, apartado 23. STJCE C103/05, Rec. p. 16827, asunto Reisch Montage, apartado 22. STJCE C98/06, Rec. p. 18319, asunto Freeport, apartado 34.
} 
Sin embargo, tal como se desprende del propio Reglamento Bruselas I, existen excepciones en las cuales la materia del litigio o la autonomía de las partes, justifica otros vínculos de conexión distintos del domicilio del demandado. Según el Reglamento 44/2001 Bruselas I ${ }^{20}$, los fueros que constituyen competencias especiales en razón de la materia, habilitan al actor para que ejerza su acción en un lugar distinto al domicilio del demandado.

Tal es el caso del fuero especial del artículo 5.3, que permite la presentación alternativa de una demanda en el lugar donde se hubiere producido o pudiere producirse el hecho dañoso ${ }^{21}$.

En nuestro caso, bajo la ocurrencia de un hecho generador que ha producido daños extracontractuales civiles y ambientales, la coherencia con el foro general domicilio del demandado, nos obliga a realizar interpretaciones restrictivas de los vínculos de conexión entre el lugar del daño y el tribunal llamado a conocer de ellos. Sin embargo, por el hecho de estar comprometidos daños civiles y daños ambientales, el análisis sobre el vínculo de conexión debe realizarse en forma separada para cada tipo de daño. Es decir, mal puede casarse la competencia judicial para el conocimiento de daños civiles a la eventual correspondencia con la competencia para daños ambientales. Una operación distintiva entre la competencia que corresponde a ambas clases de daños no afecta, en nada, al principio general actor rei forum sequitur.

En efecto, lo directo y restrictivo de la interpretación del vínculo especial de competencia en razón del daño, justificado en la previsibilidad del título de jurisdicción no puede desconocer que el foro especial ha sido establecido precisamente en razón de la situación de la víctima de un resultado dañoso, y no en razón de la situación del demandado. Incluso, algunos autores han visto en la excepción al fuero domicilio del demandado una "defensa tuitiva que pretende facilitar la defensa procesal de los intereses aparentemente más débiles"22.

En este sentido, los fueros de competencia especial por su característica de alternatividad ${ }^{23}$ respecto del fuero domicilio del demandado, se caracterizan

\footnotetext{
20 Reglamento Bruselas I Considerando 12: "El foro del domicilio del demandado debe completarse con otros foros alternativos a causa del estrecho nexo existente entre el órgano jurisdiccional y el litigio o para facilitar una buena administración de justicia".

21 STJCE C-26/91, asunto Handte, Rec. p. I-3967, apartado 14. Asimismo, Informe del Abogado General Jenard relativo al Convenio de Bruselas de 1968, DO 1979, C 59, p. 18. Texto en español, DO 1990, C 189, p. 138.

22 Reinoso Barbero, Fernando, "Foro de conveniencia, derecho de conveniencia y nulidad", Revista de Derecho UNED, № 4, 2009, p. 330.

${ }^{23}$ La alternatividad característica de otro fuero como es el artículo $6^{\circ}$ del Reglamento Bruselas I, también justifica la excepción a la regla actor rei forum sequitur. Ver: Conclusiones del Abogado General Sr. Philippe Léger, presentadas el 8 de diciembre de 2005, C539/03, asunto Roche Nederland BV y otros, Considerando 95: "En efecto, la aplicación del artículo 6, punto 1, de dicho Convenio depende de una decisión sólo del demandante y no del juez. Además y correlativamente, aunque esta decisión puede
} 
por otorgar un derecho de opción al demandante, en nuestro caso, por ser víctima de un hecho dañoso. Por su parte, establecer discriminaciones entre los hechos dañosos (máxime si son de distintas categorías de daño) va más allá de la letra y espíritu del Reglamento 44/2001 Bruselas I, el que no ha establecido diferencias entre delitos y cuasidelitos regulados por el artículo 5.3.

Este aspecto interpretativo es sustancial y precisamente caracteriza el modelo europeo en oposición, por ejemplo, al modelo estadounidense de unificación de las reglas de competencia. En efecto, mientras en el modelo estadounidense la cláusula del due process of law parte de la posición del demandado, le presume como en desventaja y, por tanto, establece una vinculación entre el demandado y el foro; en el modelo europeo, en cambio, el vínculo determinante ha evolucionado hacia el lugar del hecho dañoso ${ }^{24}$. Por tanto, en el modelo europeo la coherencia debe buscarse respecto de los lugares donde se manifiesta el hecho dañoso y no en razón del domicilio del demandado, como algún sector de la doctrina ha pretendido hacer a objeto de justificar interpretaciones restrictivas de la regla de ubicuidad.

\section{Principios de proteCCión del medio ambiente y protección De parte}

Los principios aplicables a la CJCl, constituyen directrices interpretativas sobre el objeto y fin de las normas atributivas de competencia (convencional o autónoma), para supuestos de contaminación ambiental internacional. Como principios interpretativos, deben analizarse en relación con los fines de justicia ambiental planteados por los Estados, al momento de regular un conflicto internacional.

A su vez, la construcción conceptual de desarrollo sustentable y la valoración normativamente recogida, obedece a una evolución reciente en el Derecho internacional que puede datarse en la década de los ochenta. En esta fecha se creó la Primera Estrategia Mundial para la Conservación ${ }^{25}$. Asimismo, desde el Reporte Nuestro Futuro Común ${ }^{26}$ hasta nuestros días existe una preocupación por la efectividad del concepto, circunstancia que obliga elevar el nivel de compromiso de los Estados con el desarrollo sustentable. A partir de la declaración

descansar en principios de economía procesal, puede basarse también en consideraciones más discutibles, relativas a las exigencias derivadas de una buena administración de la justicia y de la sustanciación adecuada del proceso, que las que Ilevan a un demandante, en virtud del artículo 5, punto 3, de dicho Convenio, a presentar su demanda ante el tribunal del lugar del hecho dañoso o de materialización del daño, en lugar de ante un tribunal del Estado contratante del domicilio del demandado".

24 Bajo ciertas circunstancias el modelo europeo podría ser inconstitucional a la luz del modelo estadounidense. Ver De Miguel, ob. cit., pp. 16-60; citando en este punto a Silberman, L., "Comparative Jurisdiction in the international context: will the proposed Haged Convention be Stalled", DePaul Law Review, Vol. 52, 2002, p. 331.

25 Elaborada por la Unión Mundial para la Naturaleza, 1981.

26 Informe Brundtland. Comisión Mundial sobre Medio Ambiente y Desarrollo de ONU de 1987. 
de Río y del Plan Programa 21, se intenta articular un programa coordinado que dé eficacia a la legislación medioambiental ${ }^{27}$.

Por su parte, los antecedentes convencionales (binacionales, plurinacionales y multinacionales ${ }^{28}$ sobre sistemas de responsabilidad ambiental y civil derivada, sólo constituyen excepciones, asociadas en gran medida al régimen internacional de transporte terrestre y marítimo de sustancias peligrosas o tóxicas, a proyectos de energía nuclear, o a actividades en la Antártica. En estos casos, más que distribuir las competencias jurisdiccionales, se establecen modelos de responsabilidad con interpretación estricta ${ }^{29}$.

En este sentido, la soberanía de los Estados se encuentra limitada por la responsabilidad ambiental. Desde la Conferencia de Estocolmo (1972), el Principio 21 de su Declaración sobre Medio Ambiente Humano estableció:

"Los Estados tienen, de acuerdo con la Carta de Naciones Unidas y los principios de Derecho Internacional, el derecho soberano para explotar sus propios recursos conforme a sus propias políticas ambientales, así como la responsabilidad para asegurar que las actividades dentro de su jurisdicción o control no causen daño al medio ambiente de otros estados o de áreas más allá de sus límites jurisdiccionales".

Desde esta perspectiva, la regulación de la $\mathrm{CJCl}$, basada en un modelo de soberanía, tampoco puede desconocer las limitaciones que el Derecho internacional impone a los Estados por la vía convencional, o incluso por el soft law (germen de costumbre internacional) en Declaraciones, Planes de Acción, y Cumbres, que no constituyen convenios, pero que articulan el sistema internacional de ventajas-oportunidades para un Estado en materia ambiental. De aquí que, un modelo de cooperación judicial en materia competencial civil se presente con mayor idoneidad en un modelo de justicia privada.

\footnotetext{
27 Desarrollo de los principios en: KISS, Alexandre-Charles, Droit international de l'environnement, Pedone, 1988, pp. 30-32; Thomas, Christopher y Tereposky, Greg "The Evolving Relationship Between Trade and Environmental Regulation", Journal of World Trade, 1993, pp. 23-45.

${ }^{28}$ Convenio sobre contaminación del medio marino: a) Convenio internacional sobre responsabilidad civil por daños debidos a la Contaminación por hidrocarburos, de Bruselas 1969, sustituido por el Convenio de 1992; b) Convenio internacional de constitución de un Fondo internacional de indemnización de daños causados por contaminación por hidrocarburos, de Bruselas 1971 y sus Protocolos de 1992 y de 2003; c) Convenio internacional sobre responsabilidad civil por daños debidos a contaminación por hidrocarburos para combustible de los buques, de Londres 2001 (BUNKERS 2001), d) Convenio internacional sobre responsabilidad e indemnización de daños en relación con el transporte marítimo de sustancias nocivas y potencialmente peligrosas de 1996. Contaminación por daño nuclear: a) El Convenio de la responsabilidad civil en materia de energía nuclear, de París 1960, Protocolo de 1982; b) Convenio suplementario, de Bruselas 1963 y Protocolo de 2004; c) Convenios de la International Atomic Energy Agency (IAEA) de Viena 1963 y 1997.

${ }^{29}$ Ver Convenio Internacional para prevenir la contaminación de las aguas de mar por hidrocarburos de 1977 y Convenio de Basilea sobre control de los movimientos transfronterizos de desechos peligrosos y su eliminación de1992.
} 
Sin perjuicio de lo anterior, efectos extracontractuales por daño ambiental y civil asociado, pueden causarse en negociaciones comerciales internacionales con implicancias ecológicas ${ }^{30}$. Sin duda, el tráfico de bienes y servicios lleva asociado condiciones de responsabilidad ambiental. Por esta razón, el Derecho Procesal Internacional debe estar al servicio de los principios del Derecho ambiental internacional, que actúan como directrices interpretativas para el juez, en tanto inspiran la solución del fondo del conflicto, y coadyuvan en la determinación de la $\mathrm{CJCl}$, según veremos más adelante.

Por su parte, las jurisdicciones nacionales reciben las demandas por daño ambiental, constituyendo, así, la vía más idónea -en comparación con la jurisdicción que ejercen tribunales internacionales especiales-, en el conocimiento de conflictos ambientales. En efecto, salvo los tribunales arbitrales internacionales, la justicia internacional con competencia ambiental (Corte Internacional de Justicia y Tribunales Internacionales de Derechos Humanos, principalmente), sólo se refiere a la responsabilidad estatal o establece vías indirectas que no incorporan los intereses privados.

Por esta razón, la vía nacional, que goza de un estatuto de estabilidad e imparcialidad, asegura el interés de los privados mediante la fuerza obligatoria de sus resoluciones al interior del Estado en el cual se pronuncian, o incluso hacia el exterior previo juicio de exequátur, en los países que no admiten libre circulación de sentencias judiciales al estilo europeo.

En la comunidad europea, el artículo 174 del Tratado constitutivo de la Unión Europea (TCE), recoge un alto nivel de protección ambiental, informante de un sistema integrado que permea el Derecho derivado. Fundándose en los principios de: a) cautela y acción preventiva, b) corrección en la fuente misma y c) quien contamina paga, este artículo, "justifica plenamente el recurso al principio de favorecer a la víctima", es decir, justifica lo que denominamos principio favor laesi. Así ha sido corroborado por el legislador comunitario en otro cuerpo normativo: el Reglamento 864/2007 Roma II ${ }^{31}$.

La función interpretativa, que los tribunales nacionales deben realizar en base al artículo 174 del TCE, obliga a reconocer la existencia de una pléyade de principios de Derecho ambiental internacional que inciden en la determinación

\footnotetext{
30 Tales son los casos de la Convención para la Protección de la flora, fauna y bellezas escénicas naturales de América, de Washington 1940; la Convención que Reglamenta la caza de la ballena de Washington 1946 y la que regula el Comercio Internacional de Especies Amenazadas de Fauna y Flora Silvestres de Washington, 1973; el GATT hoy Organización Mundial del Comercio (OMC); Convenios sobre Sustancias Agotadoras de la Capa de Ozono (Protocolo de Montreal de 1990); el Convenio de Basilea sobre Control de los Movimientos Transfronterizos de los Desechos Peligrosos y su Eliminación de Basilea 1989; finalmente, Tratados de Libre Comercio y Cooperación.

${ }^{31}$ Reglamento (CE) N ${ }^{\circ}$ 864/2007 del Parlamento europeo y del Consejo de 11 de julio de 2007 relativo a la ley aplicable a las obligaciones extracontractuales («Roma II»).
} 
de la $\mathrm{CJCl}$. Tales principios, se encuentras amparados bajo otros mayores tales como: a) Soberanía y de no causar daño, y b) Buena vecindad y cooperación internacional. Los cuales generan obligaciones legales internacionales basadas en la costumbre, y cuyo incumplimiento da lugar a responsabilidad internacional, siendo por tanto, obligatorias para el Estado y sus órganos jurisdiccionales ${ }^{32}$.

Así, encontramos un ejemplo de la integración de los principios ambientales internacionales en la interpretación de tribunales nacionales en el Tribunal Supremo españo| ${ }^{33}$, el que ha señalado:

"El Motivo, habida cuenta las razones, incluso, de carácter sociológico y de protección de la Ordenación Universal al Medio Ambiental aducidas, precisa subrayar 'ab initio' que, por parte de la Sala sentenciadora, se debían haber tenido en cuenta al evaluar el 'quantum' indemnizatorio derivado de esa conducta transgresora, elementales deberes, incluso, subsumibles dentro de la órbita amplia de la responsabilidad aquiliana/extracontractual -ex art. 1902 C.c.-, por cuanto que los Tribunales, cuando fijan tras la ponderación de esa conducta negligente la cuantificación de los daños irrogados, han de contemplar esas circunstancias no sólo estrictamente jurídicas o de Derecho positivo emanadas tanto del Derecho Nacional como del Derecho Internacional e, incluso del Derecho Comunitario, sino las atinentes a los distintos elementos que cualquiera que sea su procedencia económica o profesional, cultural o sociológica, sean factores determinantes o coadyuvantes en la apreciación del hecho ilícito y, sobre todo, en la verificación de los resultados dañosos (es sabido que en la complectud del dato normativo dentro de la metodología integradora, la función determinante del ilícito emergente y su sanción, debe compulsar el conjunto estructurador de lo dado; presupuestos personales, sociales, económicos, culturales, ambientales, etc.). Y es indiscutible que, esa dualidad en toda su amplitud al emitir su 'ratio decidendi' sancionadora, se tiene en cuenta por parte de los Tribunales, y en el caso de autos, caben argumentos tendentes a cuestionar su observancia en el razonamiento de la Sala 'a quo'".

A continuación enunciaremos aquellos principios ambientales que guardan relación con la determinación de la CIJ. Nuestro objetivo no consiste en hacer un desarrollo de cada principio, sino en la medida que influye en una interpretación extensiva del fuero especial del artículo 5.3 del Reglamento 44/2001 Bruselas I, por atribuir al demandante civil, como al demandante ambiental, la calidad de partes más débiles y, por tanto, más protegidas del ordenamiento público internacional.

32 SANDS, Philippe, Principles of International Environmental Law. Frameworks, Standards and Implementation, Publisher: Cambridge University Press, Vol. I, 1995, p.184.

33 STS 646/2001. Sentencia del Tribunal Supremo español. Sala de lo Civil, Madrid. No de Recurso: 72/1996. № de Resolución: 70/2001. Recurso de casación, que establece el quantum indemnizatorio de acuerdo a una interpretación a favor de la protección ambiental y protección de afectados, en relación con la tutela judicial efectiva. 
1. Principio de Soberanía sobre los Recursos Naturales y Responsabilidad de No Causar Daño al Medio Ambiente de otros Estados o de Zonas Fuera de la Jurisdicción Nacional

Expresado en la Declaración de Estocolmo ${ }^{34}$, el Principio 21, en relación con el Principio 2 de la misma Declaración ${ }^{35}$ y el Principio 2 de la Declaración de Río ${ }^{36}$, son principios que van dirigidos a los Estados, y por tanto vinculan a los órganos judiciales competentes, a fin de que conozcan de un asunto de responsabilidad por contaminación, máxime si el asunto es por responsabilidad internacional causada en contaminación transfronteriza y/o transnacional. Los jueces llamados a ejercer jurisdicción no pueden declinar su competencia sin considerar las consecuencias derivadas de estos dos principios.

\section{Principio de Cooperación Internacional}

Expresado en el Principio 24 de la Declaración de Estocolmo ${ }^{37}$, en relación con el Principio 27 de la Declaración de Río ${ }^{38}$, y llamado también de principio "de buena vecindad", es un principio enunciado con relación al

\footnotetext{
34 Declaración de la Conferencia de las Naciones Unidas sobre el Medio Humano, reunida en Estocolmo en junio de 1972, Principio 21, señala: "De conformidad con la Carta de las Naciones Unidas y con los principios del derecho internacional, los Estados tienen el derecho soberano de explotar sus propios recursos en aplicación de su propia política ambiental y la obligación de asegurar que las actividades que se lleven a cabo dentro de su jurisdicción o bajo su control no perjudiquen al medio de otros Estados o de zonas situadas fuera de toda jurisdicción nacional".

35 Declaración de la Conferencia de las Naciones Unidas sobre el Medio Humano, reunida en Estocolmo en junio de 1972, Principio 2, semana: "De conformidad con la Carta de las Naciones Unidas y los principios del derecho internacional, los Estados tienen el derecho soberano de aprovechar sus propios recursos según sus propias políticas ambientales y de desarrollo, y la responsabilidad de velar porque las actividades realizadas dentro de su jurisdicción o bajo su control no causen daños al medio ambiente de otros Estados o de zonas que estén fuera de los límites de la jurisdicción nacional".

${ }^{36}$ Declaración de la Conferencia de las Naciones Unidas sobre el Medio Ambiente y el Desarrollo, reunida en Río de Janeiro en junio de 1992. Principio 2, señala: "De conformidad con la Carta de las Naciones Unidas y los principios del derecho internacional, los Estados tienen el derecho soberano de aprovechar sus propios recursos según sus propias políticas ambientales y de desarrollo, y la responsabilidad de velar porque las actividades realizadas dentro de su jurisdicción o bajo su control no causen daños al medio ambiente de otros Estados o de zonas que estén fuera de los límites de la jurisdicción nacional".

37 Declaración de Estocolmo, Principio 24, señala: "Todos los países, grandes o pequeños, deben ocuparse con espíritu de cooperación y en pie de igualdad de las cuestiones internacionales relativas a la protección y mejoramiento del medio. Es indispensable cooperar, mediante acuerdos multilaterales o bilaterales o por otros medios apropiados, para controlar, evitar, reducir y eliminar eficazmente los efectos perjudiciales que las actividades que se realicen en cualquier esfera puedan tener para el medio, teniendo en cuenta debidamente la soberanía y los intereses de todos los Estados".
}

38 Declaración de Río, Principio 27, señala: "Los Estados y las personas deberán cooperar de buena fe y con espíritu de solidaridad en la aplicación de los principios consagrados en esta Declaración y en el ulterior desarrollo del derecho internacional en la esfera del desarrollo sostenible". 
artículo 74 de la Carta de las Naciones Unidas, en materia de cooperación ambiental internacional ${ }^{39}$. Una forma concreta de cooperación se relaciona con el diálogo judicial internacional. En efecto, desde el Derecho Internacional Privado, la $\mathrm{CJCl}$, analizada desde la perspectiva del modelo de soberanía que aún pervive en muchos ordenamientos jurídicos, y con los cuales se relacionan bilateralmente países de la comunidad europea, afectos a la aplicación de Bruselas I, arriesgan realizar una interpretación basada exclusivamente en los intereses soberanos de los Estados al momento de establecer, tanto legislativa como judicialmente los vínculos de conexión de un asunto determinado.

La buena fe y la solidaridad que señala el artículo 27 de la Declaración de Río, están dirigidas a los Estados y, por tanto, se extiende a los procedimientos judiciales. En ámbitos integrados, como el europeo, la cooperación se ha convertido en uno de los pilares de la integración ${ }^{40}$.

\section{Principio Contaminador Pagador}

Expresamente referido en el artículo 174 del TCE, y recogido en el Principio 16 de la Declaración de Río ${ }^{41}$, este principio, se materializa tanto en normas de fondo sobre responsabilidad civil y responsabilidad por daño ambiental como en la redistribución de los costos de la litigación internacional ${ }^{42}$. El principal problema asociado a la $\mathrm{CJCl}$ consiste en determinar la extensión del principio contaminador pagador, es decir, determinar cuáles son los costos que debe asumir el contaminador, y si en ellos se encuentran los costos de la litigación internacional, conocidos como cargas de internacionalidad, y que alteran el vínculo en razón de haber operado un principio favor laesi, o un fuero especial en razón de la calidad del demandante.

\footnotetext{
39 Conocido a propósito del Proyecto Gabcikovo-Nagymaros, Hungría vs. Checoslovaquia, ante la Corte Internacional de Justicia, alegada que fuere cooperación de buena fe y el desarrollo progresivo del Derecho ambiental.

40 Betlem, Guerrit; Hondius, Ewoud, "European Private Law after the Treaty of Amsterdam", European Review of Private Law, Netherlands, 2001, pp. 3-20.

41 Declaración de Río, Principio 16, señala "Las autoridades nacionales deberían procurar fomentar la internalización de los costos ambientales y el uso de instrumentos económicos, teniendo en cuenta el criterio de que el que contamina debe, en principio, cargar con los costos de la contaminación, teniendo debidamente en cuenta el interés público y sin distorsionar el comercio ni las inversiones internacionales".

42 Montenegro Arriagada, Sergio; Hervé, Dominique; Durán Medina, Valentina, Los Tratados Ambientales: principios y aplicación en Chile, Edic. Edición: Marie Claude Plumer Bodin. 1ª ed. Santiago de Chile: CONAMA, 2001.
} 
El asunto no ha sido pacífico en la doctrina ${ }^{43}$, pues la extensión del principio contaminador pagador hará viable o no las medidas de prevención, manejo, reducción y garantía de no repetición. Por nuestra parte, creemos que el principio incluye asumir los costes privados y los costes de la gestión pública judicial (y administrativa) en la recuperación del medio ambiente. Tal cosa consiste en atribuir toda la carga de la internacionalidad al demandado de contaminación ambiental y de daños civiles directos asociados.

\section{Principio de la Responsabilidad común pero diferenciada}

Enunciado en el Principio 7 de la Declaración de Río ${ }^{44}$, es una manifestación de equidad en el derecho internacional general, que tiene especial relevancia en las relaciones entre países desarrollados y aquellos que no lo son, en lo referente a la asunción de responsabilidades ambientales. En lo relacionado a la $\mathrm{CJCl}$, cabría concluir que desde la perspectiva de los Estados desarrollados que siguen la doctrina del forum non conveniens, el análisis sobre su competencia debe tener también en consideración este principio, así como los conceptos: "recursos compartidos", "patrimonio común de la humanidad" o "interés común de la humanidad". Asimismo, existen Convenciones que han incluido este principio con carácter vinculante ${ }^{45}$.

\section{CONCLUSIONES}

A diferencia del modelo estadounidense, conforme al cual la cláusula del due process of law supone a priori que el demandado está en situación de desventaja; en el modelo europeo, en cambio, el vínculo de conexión tiende a objetivarse, y por tanto, toma distancia de los sujetos que intervienen.

Por otra parte, los argumentos entregados en este trabajo no se han fundado en la calidad "de parte más débil" que perfectamente podría alegarse del demandante de un daño ambiental y de un daño civil asociado. Este trabajo

\footnotetext{
${ }^{43}$ SMETS, Henri, "Les exceptions admises au principe pollueur payeur The exceptions to the polluterpayer principle", Droit et Pratique du Commerce International, T. 20 № 2, 1994, pp. 211 y ss.

${ }^{44}$ Enunciado anteriormente en la Declaración de Estocolmo, bajo la forma del Principio 23, señala: "Los Estados deberán cooperar con espíritu de solidaridad mundial para conservar, proteger y restablecer la salud y la integridad del ecosistema de la tierra. En vista de que han contribuido en distinta medida a la degradación del medio ambiente mundial, los Estados tienen responsabilidades comunes pero diferenciadas. Los países desarrollados reconocen la responsabilidad que les cabe en la búsqueda internacional del desarrollo sostenible, en vista de las presiones que sus sociedades ejercen en el medio ambiente mundial y de las tecnologías y los recursos financieros de que disponen".

45 Convenio de Viena para la protección de la capa de ozono de 1985 y el Protocolo de Montreal sobre Sustancias que agotan la capa de ozono de 1987; Convención Marco de las Naciones Unidas sobre Cambio Climático de 1992 y sus Protocolos.
} 
ha seguido la senda de la objetivación, basándose en la argumentación de los principios envueltos.

En este sentido, el fuero "lugar del hecho dañoso", no puede determinarse tomando como principal consideración el domicilio del demandado por ser éste el lugar que, generalmente, coincidirá con el hecho generador del daño, ni menos aún porque así se haya decidido para otros casos de daño civil. Porque, cuando el daño civil al que nos referimos está asociado a un daño ambiental, con el cual comparte el mismo hecho generador, entonces el fuero "lugar del hecho dañoso" debe considerar la protección internacional del medio ambiente.

Así, el problema sobre la extensión del fuero consiste en compatibilizar los principios de Derecho Internacional Privado sobre jurisdicción competente con los principios de protección ambiental.

\section{BibLIOGRAFÍA}

\section{Referencias Bibliográficas}

Betlem, Guerrit; Hondius Ewoud, "European Private Law after the Treaty of Amsterdam", European Review of Private Law, Netherlands, 2001.

Calvo CaravacA, Alfonso-Luis, "El Derecho internacional privado en la comunidad europea", Anales del Derecho № 21, Universidad de Murcia, 2003.

De Miguel Asensio, Pedro Alberto, "El futuro del Derecho Privado uniforme en la unión europea: Nuevas tendencias y retos", Spanish Yearbook of International Law, Vol. XI, 2005.

Fallon, Marc, "Le principe de proximité dans le droit de l'Union européenne", en Lagarde, Mélanges P., Dalloz, París, 2005.

, "Les conditions d'un code européen de droit international privé", en Fallon, M.; Lagarde, P.; Poillot-Peruzzetto S. (Edits.), La matière civile et commerciale, socle d'un code européen de droit international privé?, Dalloz, Paris, 2009.

Fernández Arroyo, Diego, "Competencia internacional exclusiva y exorbitante de los jueces de los Estados miembros de la Unión Europea ¿hasta cuándo?", Jurídica: Anuario del Departamento de Derecho de la Universidad Iberoamericana No 34, 2004.

Garau Sobrino, Federico, Lecciones de Derecho Procesal Civil Internacional, Universitat de les Illes Balears, España, 2003.

Kıss, Alexandre-Charles, Droit international de l'environnement, Pedone, 1988.

LAGARDE, Paul, "Le principe de proximité dans le droit international privé contemporain", Recueil des cours de l'Académie de Droit International de La Haye T. 196, 1986. 
Montenegro Arriagada, Sergio; Hervé, Dominique; Durán Medina, Valentina, los Tratados Ambientales: principios y aplicación en Chile, Edic. Edición: Marie Claude Plumer Bodin. $1^{\text {a }}$ ed. Santiago de Chile: CONAMA, 2001.

Otero García-Castrillón, Carmen, "Problemas de aplicación de las normas de competencia judicial internacional en el Derecho español y comunitario: reflexiones en torno a la doctrina del forum non conveniens", Revista de la Facultad de Derecho de la Universidad Complutense No 94, 2000.

Pérez Vera, Elisa; González Campos, Julio, Derecho Internacional Privado Vol. I, UNED, España, UNED, 2001.

Reinoso Barbero, Fernando, "Foro de conveniencia, derecho de conveniencia y nulidad", Revista de Derecho UNED No 4, 2009.

ROdRíGuez Jiménez, Sonia, Competencia Judicial Internacional, Instituto de Investigaciones Jurídicas, Universidad Nacional Autónoma de México, 2009. Conexidad y Litispendencia Internacional en el Derecho internacional privado mexicano, Instituto de Investigaciones Jurídicas, Universidad Nacional Autónoma de México, 2009.

"La Competencia Judicial Internacional. Dos aspectos para reflexionar", Revista de la Facultad de Derecho de México, № 251, 2009.

Romero Seguel, Alejandro, "La falta de jurisdicción y la denuncia en el proceso: las excepciones procesales y materiales", Revista Chilena de Derecho Vol. $31 \mathrm{~N}^{\circ} 12004$.

SANDS, Philippe, Principles of International Environmental Law. Frameworks, Standards and Implementation, Publisher: Cambridge University Press, Vol. I, 1995.

Silberman, L, "Comparative Jurisdiction in the international context: will the proposed Haged Convention be Stalled", DePaul Law Review Vol. 52, 2002.

SMETS, Henri, "Les exceptions admises au principe pollueur payeur The exceptions to the polluter-payer principle", Droit et Pratique du Commerce International T. 20, № 2, 1994.

Thomas, Christopher; Tereposky, Greg, "The Evolving Relationship Between Trade and Environmental Regulation", Journal of World Trade, 1993.

Virgós Soriano, Miguel, Garcimartín Alférez, Derecho Procesal Civil Internacional Litigación Internacional, 2ª Edición, Thomson Civitas, Pamplona, 2007.

\section{Informes y Documentación}

Informe Brundtland. Comisión Mundial sobre Medio Ambiente y Desarrollo de ONU de 1987.

Informe del Abogado General Jenard relativo al Convenio de Bruselas de 1968, DO 1979, C 59, p. 18. Texto en español, DO 1990, C 189. 
3. Sentencias del Tribunal de Justicia de las comunidades europeas

STJCE 56/79, asunto Zelger vs. Salinitri.

STJCE C-256/00, asunto Besix SA, apartados 31-35.

STJCE C-167/00 caso Henkel.

STJCE C4/03, asunto Gesellschaft für Antriebstechnik mbH \& Co. KG y Lamellen und Kupplungsbau Beteiligungs KG, apartado 21.

STJCE C343/04, asunto Land Oberösterreich contra EZ, apartados 27-29.

STJCE C73/04, asunto Brigitte y Marcus Klein y Rhodos Management Ltd, apartados 14-16.

STJCE C-116/02, asunto Erich Gasser GmbH vs. MISAT Srl., apartado 38.

STJCE C539/03, asunto Roche Nederland BV y otros vs. Frederick Primus, Milton Goldenberg, apartado 36.

STJCE 33/78 Asunto Somafer vs. Saar-Feerngas.

STJCE C-26/91 asunto Jakob Handte vs. Mecano Chimoques.

STJCE C-440/97 asunto GIE Groupe Concorde y otros vs. Capitaine commandant le navire "Suhadiwarno Pnajan" y otros.

STJCE C-96/00 asunto Rudolf Gabriel.

STJCE C-256/00 asunto Besix.

STJCE C-334/00 asunto Fonderie Officine Meccaniche Tacconi SpA.

STJCE, C89/91, Rec. p. I139, asunto Shearson Lehman Hutton, apartado 14.

STJCE C265/02, Rec. p. 11543, asunto Frahuil, apartado 23.

STJCE C103/05, Rec. p. I6827, asunto Reisch Montage, apartado 22.

STJCE C98/06, Rec. p. I8319, asunto Freeport, apartado 34.

STJCE C-26/91, asunto Handte, Rec. p. I-3967, apartado 14.

\section{Sentencias de tribunales comunitarios}

STS 646/2001. Sentencia del Tribunal Supremo español. Sala de lo Civil, Madrid. $N^{\circ}$ de Recurso: 72/1996. N No de Resolución: 70/2001. Recurso de casación.

5. Conclusiones de Abogado General del Tribunal de Justicia de las Comunidades europeas

Conclusiones del Abogado General Sr. F.G. Jacobs, de 18 de septiembre de 2003, C-18/02, Asunto DFDS Torline A/S contra SEKO Sjöfolk Facket för Service og Kommunikation.

Conclusiones del Abogado General Sr. Paolo Mengozzi, de 24 de mayo de 2007, C98/06, asunto Freeport plc contra Olle Arnoldson. 
Conclusiones del Abogado General Sr. L.A. Geelhoed de 31 de enero de 2002, C-334/00, asunto Fonderie Officine Meccaniche Tacconi Spa, apartados 28-30.

Conclusiones del Abogado General Sr. Philippe Léger, presentadas el 8 de diciembre de 2005, C539/03, asunto Roche Nederland BV y otros, Considerando 95.

\section{Convenios y Declaraciones}

Convenio de Bruselas, de 27 de septiembre de 1968, relativo a la competencia judicial y a la ejecución de resoluciones judiciales en materia civil y mercantil. Modificado respectivamente por los Convenios de Adhesión.

Convenio de Lugano, de 16 de septiembre de 1988, relativo a la competencia judicial y a la ejecución de resoluciones judiciales en materia civil y mercantil.

Convenio de Viena para la protección de la capa de ozono de 1985.

Protocolo de Montreal sobre Sustancias que agotan la capa de ozono de 1987.

Convención Marco de las Naciones Unidas sobre Cambio Climático de 1992 y sus Protocolos.

Acuerdo entre la Comunidad Europea y el Reino de Dinamarca relativo a la competencia judicial, el reconocimiento y la ejecución de resoluciones judiciales en materia civil y mercantil. Sustituido por el Convenio de Bruselas de 1968 y firmado en Bruselas el 19 de octubre de 2005.

Convenio de Bruselas de 27 de septiembre de 1968 y en el Convenio de Lugano de 16 de septiembre de 1988, relativos a la competencia judicial, el reconocimiento y la ejecución de resoluciones judiciales en materia civil y mercantil.

Declaración de la Conferencia de las Naciones Unidas sobre el Medio Humano, reunida en Estocolmo en junio de 1972.

Declaración de la Conferencia de las Naciones Unidas sobre el Medio Humano, reunida en Estocolmo en junio de 1972.

Declaración de la Conferencia de las Naciones Unidas sobre el Medio Ambiente y el Desarrollo, reunida en Río de Janeiro en junio de 1992.

Convenio internacional sobre responsabilidad civil por daños debidos a la Contaminación por hidrocarburos, de Bruselas 1969, sustituido por el Convenio de 1992.

Convenio internacional de constitución de un Fondo internacional de indemnización de daños causados por contaminación por hidrocarburos, de Bruselas 1971 y sus Protocolos de 1992 y de 2003. 
Convenio internacional sobre responsabilidad civil por daños debidos a contaminación por hidrocarburos para combustible de los buques, de Londres 2001 (BUNKERS 2001).

Convenio internacional sobre responsabilidad e indemnización de daños en relación con el transporte marítimo de sustancias nocivas y potencialmente peligrosas de 1996.

Convenio de la responsabilidad civil en materia de energía nuclear, de París 1960, Protocolo de 1982.

Convenio suplementario, de Bruselas 1963 y Protocolo de 2004.

Convenios de la International Atomic Energy Agency (IAEA) de Viena 1963 y 1997.

Convenio Internacional para prevenir la contaminación de las aguas de mar por hidrocarburos de 1977.

Convenio de Basilea sobre control de los movimientos transfronterizos de desechos peligrosos y su eliminación de1992.

Convención para la Protección de la flora, fauna y bellezas escénicas naturales de América, de Washington 1940.

Convención que Reglamenta la caza de la ballena de Washington 1946.

Convención reguladora del Comercio Internacional de Especies Amenazadas de Fauna y Flora Silvestres de Washington, 1973.

Convenios sobre Sustancias Agotadoras de la Capa de Ozono (Protocolo de Montreal de 1990).

Convenio de Basilea sobre Control de los Movimientos Transfronterizos de los Desechos Peligrosos y su Eliminación de Basilea 1989.

7. Reglamentos comunitarios

Reglamento (CE) No 864/2007 del Parlamento europeo y del Consejo de 11 de julio de 2007 relativo a la ley aplicable a las obligaciones extracontractuales («Roma II»).

Reglamento (CE) No 44/2001 del Consejo, de 22 de diciembre de 2000, relativo a la competencia judicial, el reconocimiento y la ejecución de resoluciones judiciales en materia civil y mercantil (Bruselas I). 
